\title{
PANDEMICS ARE EARTH CLEANSERS: IT IS AN EYE OPENER
}

\author{
Sabir Khan ${ }^{1}$ and Shilpi Yadav ${ }^{2}$ \\ ${ }^{1}$ Research Assistant, Department of Geography, Sophia Girls' College, Ajmer, (Raj.) India \\ Email: sabirkhan89.gis@gmail.com \\ ${ }^{2}$ Assistant Professor, Department of Geography, Sophia Girls' College, Ajmer, (Raj.) India \\ Email: shilpiyadav.gis@gmail.com
}

\begin{abstract}
A crisis gives us the opportunity to practice our creativity, for it makes us think outside the box" (Abhijit Naskar). In this negativity let's spread some positivity. So, we can easily face the pandemic situation and we will do something for our country or nature. "Life calls the tune, we dance." (John Galsworthy). This statement is very true that we all are dancing to the tune of coronavirus which Nature is playing for the improvement of the environment while man suffers, nature prospers. The coronavirus is changing everything from air services to the economic activities - and it's also having a big impact on the environment. Some of those are positive - a large (albeit likely temporary) drop in carbon dioxide emissions as factories close and the economy stutters - while others are negative. COVID-19 is causing global trade to be disrupted, flights are being cancelled, and many people are now working or staying at home. Life, as we know it, has changed beyond all recognition...for the moment. Coronavirus has taken a lot of lives across the world until now. As soon as we switch on the television or the radio our ears are flooded with similar negative news from all around the world. To prevent the spread of COVD-19, governments of different nations are taking multiple steps and doing all that can be done to control the spread of the virus. However, if we pay close attention to everything that is happening around us owing to the spread of this virus, we will notice that all the negative effects of coronavirus are restricted to mankind only. As far as our owners of the earth are concerned, the flora and fauna as well as nature itself, are enjoying the positives from this deadly virus. It seems as if the plants and animals are reclaiming the land that we forgot to share with them or rather snatched from them. Also, it is quite vivid that the environment seems to have pressed the hidden reset button that it had, to replenish itself. All of these can be categorized as the positive side effects of COVID-19. But it is also having some interesting positive effects on the environment such as Clear Sky, Pollution free, go for green, self-awareness regarding the environment, responsibilities towards the country, lack of pressure on resources, family united again etc.
\end{abstract}

Key words: Corona Virus; Environment; Air Pollution, Water Pollution, Resources, Economy

\section{Introduction}

The wealth of the nation is its air, water, soil, forests, minerals, rivers, lakes, oceans, scenic beauty, wildlife habitats and biodiversity... that's all there is. That's the whole economy. That's where all the economic activity and jobs come from. These biological systems are the sustaining wealth of the world (Gaylord Nelson). This statement is apt into this pandemic situation because we all are forgetting about nature as we run behind the economy. But we don't understand that our economy is totally based on nature, or we can say directly or indirectly our all actions are associated with the environment. Nowadays, we all can see that because of our greediness towards the economy, the whole world is suffering due to this virus. And this pandemic situation makes for reflection for everyone. Coronavirus threatens humanity; every country has suffered due 
to this virus. Many thousands of people have died every day. This is a very critical or negative situation for everyone. But in this negativity there is some positivity is also found. We can see the environment again flourish day by day. The impact of coronavirus on the environment is positive. Here are eight ways coronavirus is already having an effect:

1. Air Pollution

2. Water Pollution

3. Consumption of $\mathrm{Co}_{2}$ is a decrease

4. Climate Change

5. Wildlife / Fauna

6. Go Green Concept

7. National \& International Unity

8. Inverse Relation between environment and the Economy of the Nation.

\section{No Crisis of Air Pollution / Lowered Pollution}

Transport makes up 23 percent of the world's global carbon emissions (The International Air Transport Association (IATA)), but thanks to airports closing and companies like Emirates grounding their flights, there are fewer planes in the sky, meaning a lot fewer air pollutants and greenhouse gases being emitted. In fact, not only has this led to less pollution in the air, but air quality has improved significantly, and the earth's ozone layer is cooling down and recovering. One of the main impacts of the coronavirus outbreak has been a significant drop in air pollution in many parts of the world. Most notably seen in developed, or developing, industrial nations like China, India, USA and in Europe, the drop shows just how much industrial activity has been shut down as of late. Satellite imagery from the likes of NASA and the European Space Agency (ESA) has been seen by many experts as "the largest scale experiment ever" in terms of reduction in emissions around the world. Data from satellites like the ESA's Sentinel-5P Satellite over the last few weeks have shown a significant drop in polluting gases like nitrogen dioxide $\left(\mathrm{NO}^{2}\right)$.

Nitrogen dioxide is mainly produced by car engines, power plants, and other industrial processes; it is believed that be the cause for a myriad of health problems, especially respiratory illnesses like asthma. One of the largest drops in the gas has been seen in Wuhan, Central China. The city has been under strict lockdown since January.
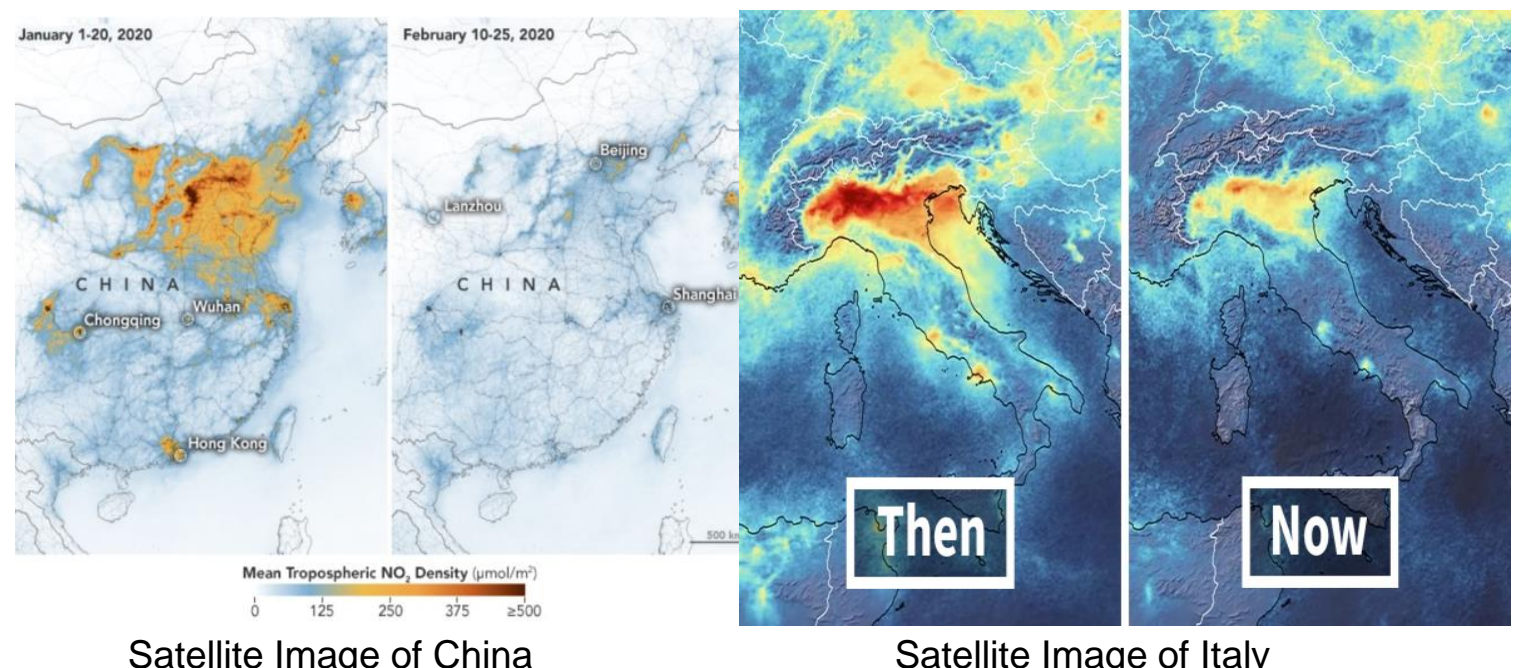

Satellite Image of China

Satellite Image of Italy

Most of its 11 million inhabitants have been confined to their homes and industry, plus travel effectively came to a halt. This resulted in a 10-30 percent drop in emissions over the period. The 
above satellite images of China and Italy taken by NASA. You can see the $\mathrm{NO}_{2}$ level drop down up to the 30 percent approx within one year.

\section{Air Pollution in India}

In India, Delhi is one of the most polluted Cities is World. It is PM 2.5 AQI (Air Quality Index) is about 858 in 2019 but after lockdown, the PM 2.5 AQI is 42 at present. Indian cities are breathing easy. Air quality in Delhi, notorious for being the worst in the world, is now a "healthy zone" thanks to the nationwide, 21-day lockdown to contain the spread of Covid-19. Other metropolitan and tier2 cities too are witnessing a similar trend.

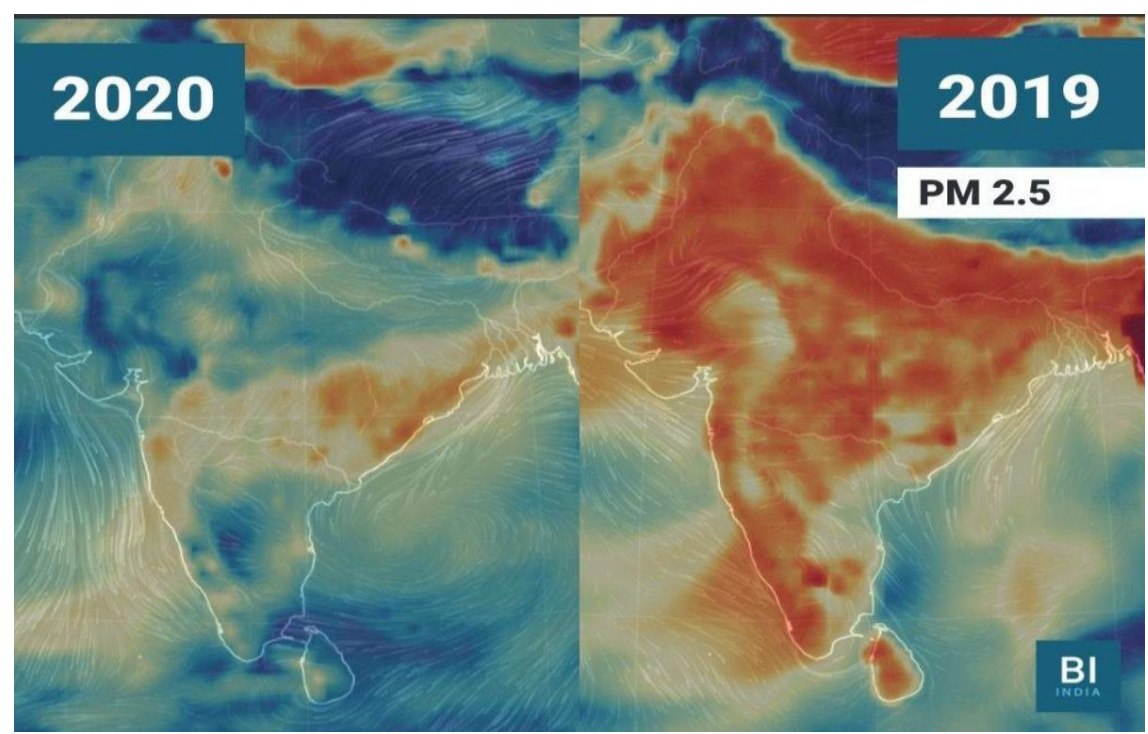

Air Quality difference within one year in India

Since March 25, India has shut down offices, schools, cinema halls, malls, markets, and non-essential service providers. All modes of public transport such as metro trains, buses, interstate trains, and domestic and international flights for civilian movement have also been stopped.

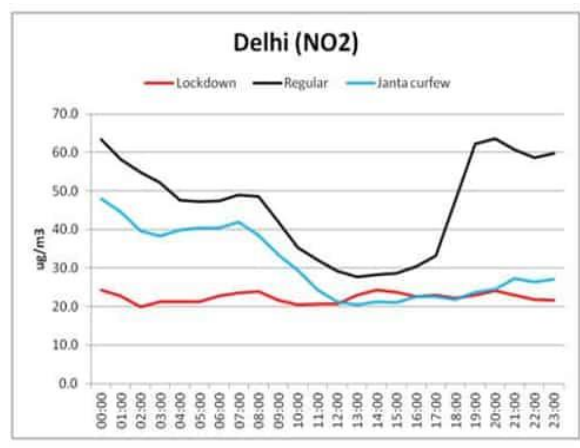

Note: Average of 37 stations

Source: CSE analysis based on CPCB realtime data

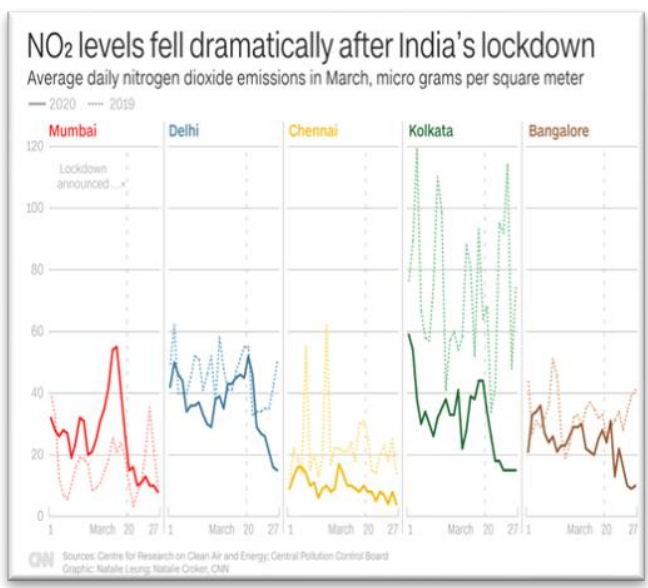

In this graph you can see how much the $\mathrm{NO}^{2}$ emission has decreased after lockdown in India. 


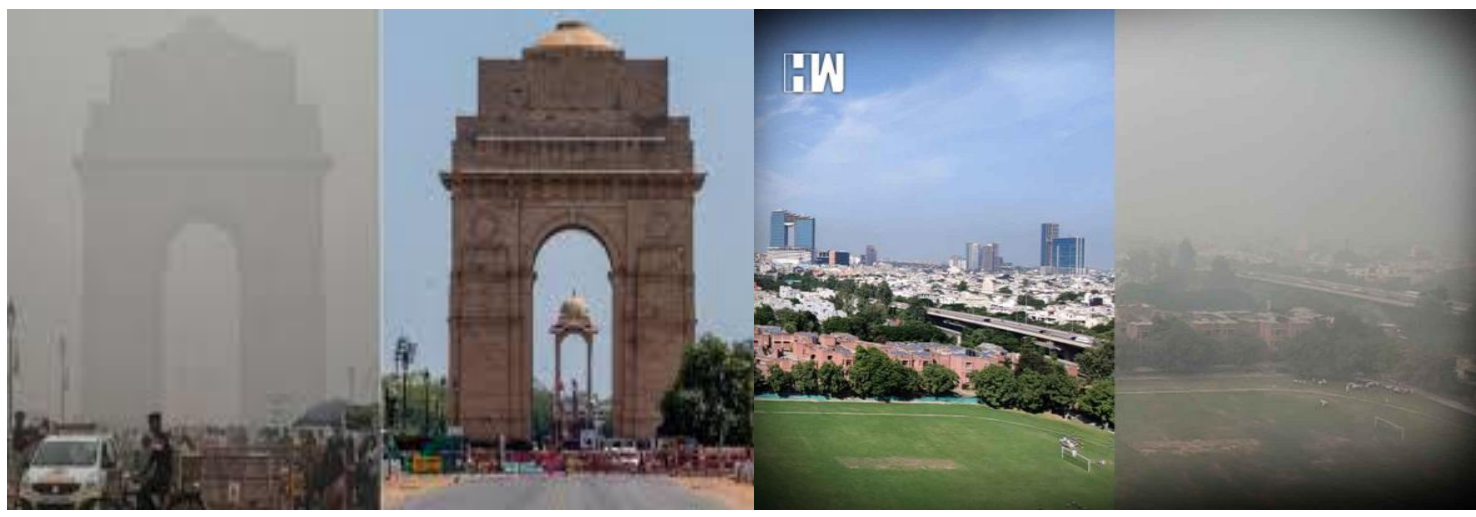

Air Quality difference in Delhi City (Source: www.hindustantimes.com)

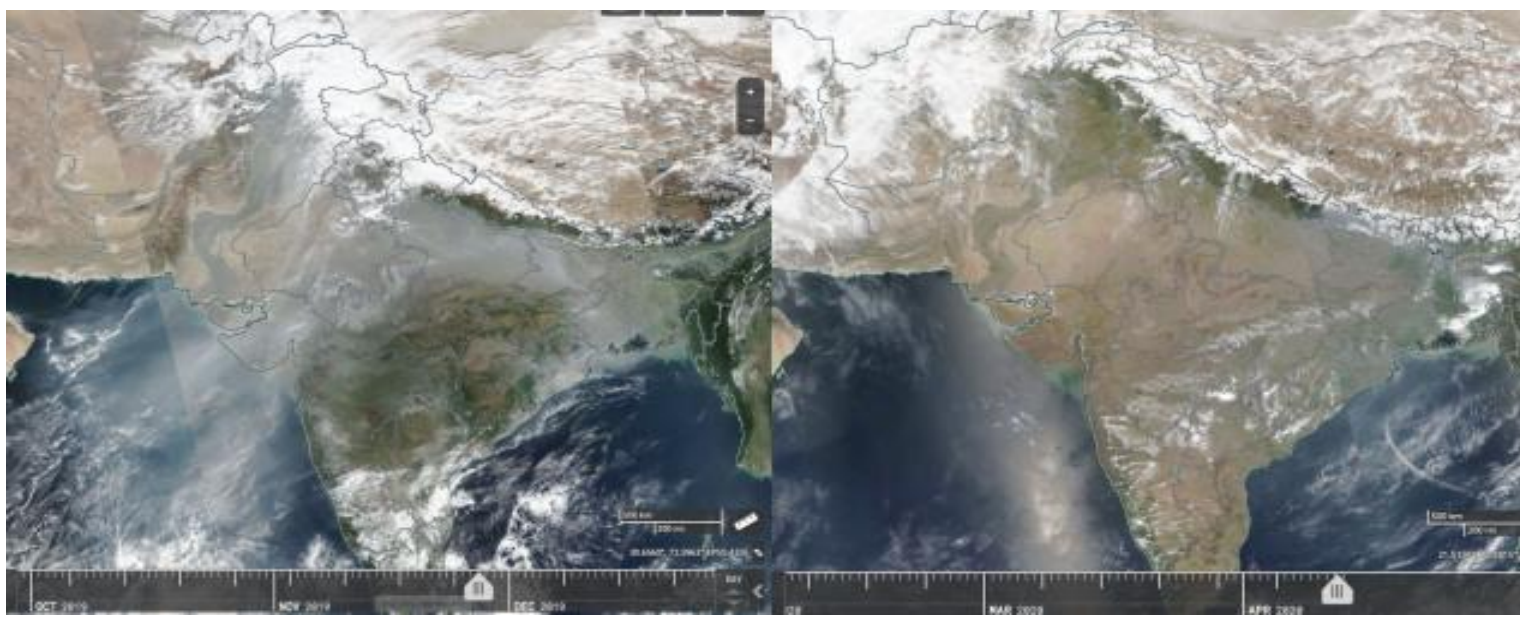

Satellite images show a significant reduction in haze caused by pollution across northern India and Pakistan from the middle of November 2019 compared to April 12, 2020.

\section{No Crises of River Pollution}

The Venice canals are clearer than ever...

Italy may be suffering from some of the worst cases of Coronavirus but perhaps a small victory for the country is that the canals of Venice now boast crystal clear waters. With tourists numbers culled because of the virus, the waters in Venice's canals are cleaner than they have been in living memory. With things like motorboats effectively "grounded", sediment churning and other water pollutants have dropped dramatically. In most areas of Venice, residents have been amazed by how clear the water has become. So much so, in fact, that fish can be seen once again in the canals. Similarly, China's rivers are also clean due to the lockdown.

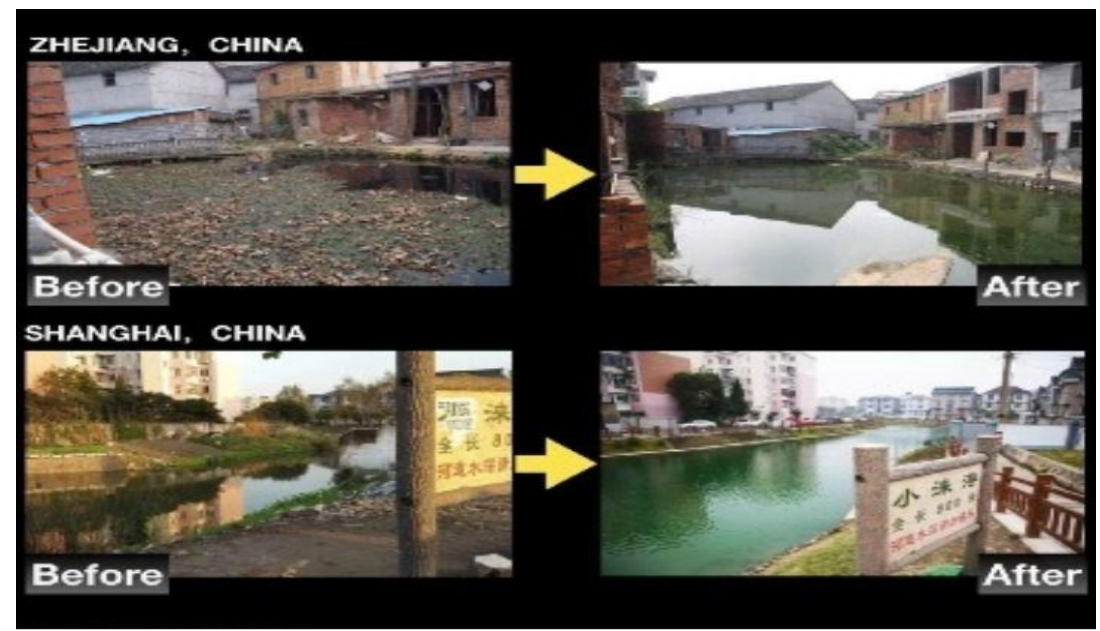




\section{After A Long Time India is Free from Water Pollution}

River Yamuna: The River Yamuna Water is clearer than the past few years and lockdown may explain this. In the lockdown situation many industrial units are shut. That is why the flow of pollutants is not taking place in the river. Within 9 days of the lockdown, the water of river Yamuna was clean, this is also a signal that we should take care of the nature, and we should be with the environment". It seems that the way Corona affects our body similarly these contaminated pollutants are also affect the body of rivers which makes river died“. Therefore the government should avoid the flow of contaminated water or pollutants in the water bodies and government should make a proper functioning plan for industrial pollutants. River Ganga is the holy river for India, but due to religious rituals and culture, this river water is also contaminated. After the lockdown this river is also clean because of lack of tourism activities now days.
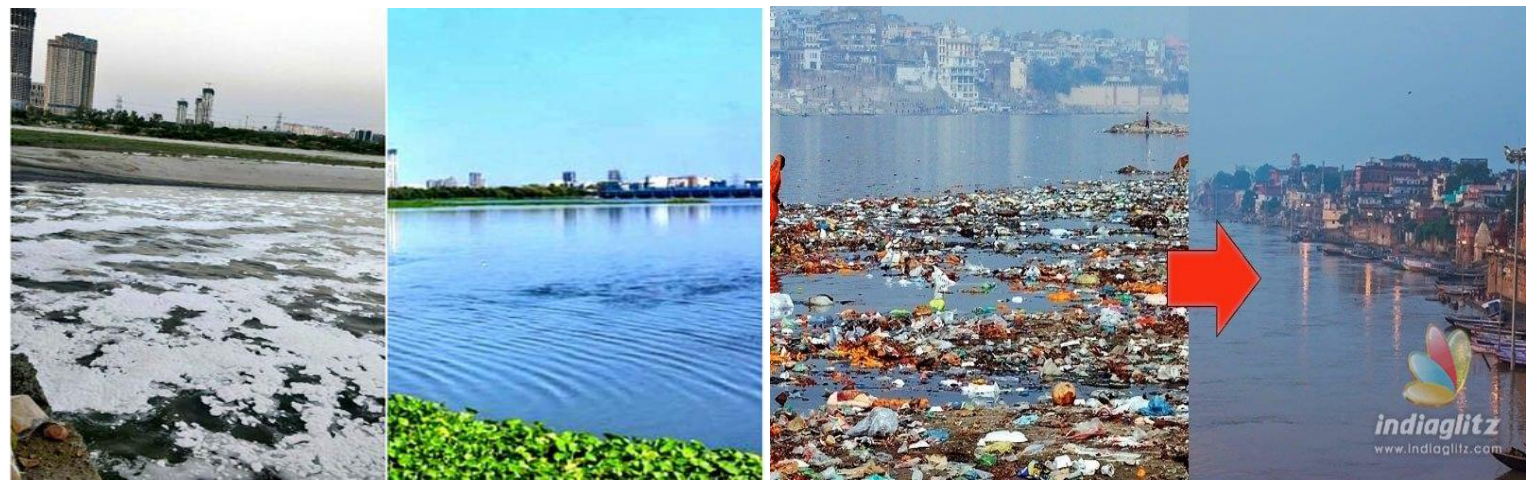

River Yamuna \& River Ganga (Before \& After)

\section{Wildlife / Animal Life}

Sea turtles laid sixty million eggs thanks to empty beaches...Pollution levels have reduced drastically and animals are reclaiming the streets. Coronavirus seems to be helping nature recoup. There is good news from Orissa where the Olive Ridley sea turtles have arrived for nesting and the lockdown is providing perfect conditions for them. They have come in thousands along the sixkilometre long Rushikulya beach of Orissa's Ganjam district in the last five days. These rare sea turtles known for mass nesting, come to the Orissa coast every year for nesting. According to the Orissa Wildlife Organization (OWO), nearly 50 percent of the world's Olive Ridley turtle population comes here to reproduce.

\section{Climate is no Longer the Crisis}

In the world, the climatic crisis is no longer; due to the Coronavirus, everyone is lockdown and stayed at home. No one moves outside of their houses. All the Social, Cultural and Economic activities are shut. That is why the pollution level has decreasing day by day. We can see a clear blue sky; temperature is also decreased with no traffic congestion, Quality of Air is good nowadays. This is a good signal for us.

\section{No Traffic Congestion}

Shutting down the educational institutes, offices, industries and practically everything places where people would gather in large masses or numbers during the 30 days of lockdown. Movement is restricted. No one is traveling. Movement of vehicles or traveling is strictly restricted, especially in cities like Jaipur, Delhi, Bangalore, Mumbai, Hyderabad, Kolkata etc. This has significantly reduced travel time for emergency services. For example, a cab drive from Kukas to Bagru in Jaipur would otherwise take 1 hour and 45 minutes, which has now been reduced to just 40 minutes only. 


\section{No Noise Pollution}

'No Honking' I No Horn Please means no noise pollution was one of the most flouted rules especially in the large cities like Delhi and Mumbai as passengers would use loud horns near a hospital or medical infrastructure and educational zones. As we are now in self-isolation or quarantine due to lockdown, again the sounds of birds chirping are a blessing for humanity. Birds are spreading happiness in this negativity with their chirping sound.

\section{Reducing Carbon Emission}

Scientists have been requesting countries for years to take action toward decreasing carbon consumption. This is the first time in history that all carbon-producing economies have gone under lockdown at the same time. Amazing results were found. NASA has revealed that levels of carbon monoxide were 30-45 percent reduction in the atmosphere in China in especially February and early March in the year 2020, compared to the same period in 2019. In Delhi, the air quality is also 'Good' \& 'Pure" and people are happy a posting pictures of the pollution-free city and clear blue sky on social media like Facebook, Twitter, Instagram etc.

\section{Inverse Relation between Environment and Economy of the Nation}

We can see that whenever the economy diminishes, carbon emission also decreases; on the other hand, the environment flourishes day by day. In this graph, you can see that economy drop in 2008 when the global financial crises, so carbon emission also went down, similarly in the Asian Financial crisis, Fall of the USSR, Second Oil Crisis, First Oil Crisis \& Corona Virus pandemic, in all this crisis or situation economy definitely drop down side by side carbon emission was also reduced, meanwhile the environment flourishes.

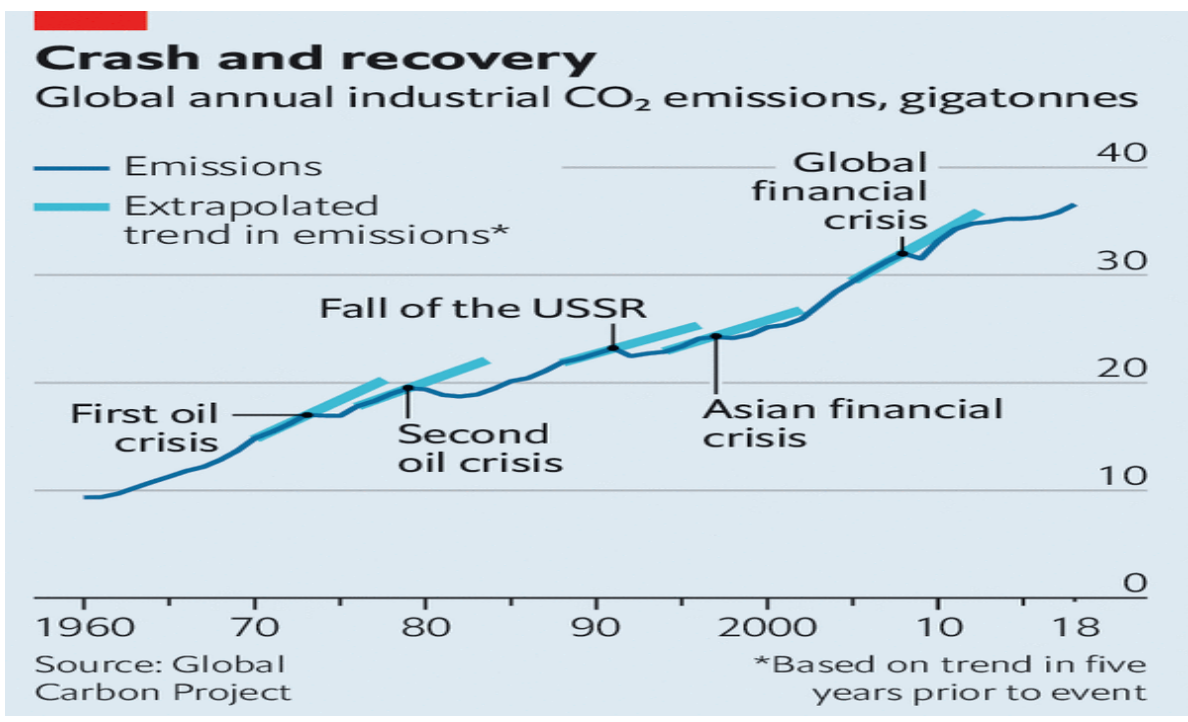

\section{International Unity}

Last but not the least; countries have pushed aside trade wars, border disputes, illegal immigration and other issues. Rival countries have joined their hands in fighting the common enemy (Covid - 19). Many countries are offering help to each other in the testing times. Like India is to supply these essential drugs to approx. 50 countries who have been particularly badly affected by pandemic; countries like the United States, Spain, Italy etc. have been seeking India's help to allow the sale of hydroxychloroquine tablets to treat the growing number of coronavirus patients 


\section{Conclusion}

Short Term Positive Impact: It's just a temporary effect. It won't cause any drop in the climate change which has been the favourite activity to work upon of our specie. Not even a bit. Just as the lockdown is lifted we responsible human beings are going to cover-up all these few changes which have come during the lockdown with an overwhelming faster rate. So stop celebrating. Years of stabbing requires years of medication and care. Unless major steps are taken towards maintaining the current environmental situation for at least 10 years, no differentiable difference would be visible next year. Increasing PM 2.5 is the major cause of Asthma. Every year so many people lost their lives due to the Asthmatic attack. 4 Million Deaths from PM 2.5 worldwide every year. At present scenario PM2.5 level is dropping rapidly, so definitely the death rate should also decreased. So one of the studies of China, tell if we compare the mortality rate with PM 2.5 (Air Quality), Corona virus lock down likely saved 77,000 lives in China just by reducing air pollution. If we control the PM 2.5 levels in our country, so we can easily control over the death causalities worldwide.

\section{References}

1. "Is sea level rising?" National Oceanic and Atmospheric Administration. Archived from the original on 2020-02-18. Retrieved 2020-04-06.

2. "Climate Change". National Geographic Society. 2019-03-28. Archived from the original on 2019-12-31. Retrieved 2020-04-06.

3. Madhav, Nita; Oppenheim, Ben; Gallivan, Mark; Mulembakani, Prime; Rubin, Edward; Wolfe, Nathan (2017). Jamison, Dean T.; Gelband, Hellen; Horton, Susan; Jha, Prabhat (eds.), "Pandemics: Risks, Impacts, and Mitigation", Disease Control Priorities: Improving Health and Reducing Poverty (3rd ed.), The International Bank for Reconstruction and Development / The World Bank, doi:10.1596/978-1-4648-0527-1/pt5. ch17 (inactive 202004-13), ISBN 978-1-4648-05271, PMID 30212163, archived form the original on 2020-0323, retrieved 2020-04-06.

4. Kopnina, Helen; Washington, Haydn; Taylor, Bron; J Piccolo, John (2018-02-01). "Anthropocentrism: More than Just a Misunderstood Problem". Journal of Agricultural and Environmental Ethics. 31 (1): 109-127. doi:10.1007/s10806-018-9711-1.

5. Rull, Valentí (2016-09-01). "The humanized Earth system (HES)". The Holocene. 26 (9): 1513-1516. Bibcode: 2016 Holoc.26.1513R. doi:10.1177/0959683616640053.

6. cosmopolitanme.com/life/coronavirus-is-having-a-really-positive-impact-on-the-environment

7. https://interestingengineering.com/7-ways-the-coronavirus-is-affecting-the-environment.

8. https://www.cnbctv18.com/healthcare/coronavirus-pandemic-10-ways-in-which-thelockdown-is-helping-people-and-the-environment-5580881.htm 